\title{
Use of environmental parameters to explain the variability in spawner- recruitment relationships of Namibian sardine Sardinops sagax
}

\author{
CH Kirchner*, CH Bartholomae and A Kreiner \\ National Marine Information and Research Centre, Ministry of Fisheries and Marine Resources, PO Box 912, Swakopmund, \\ Namibia \\ * Corresponding author, e-mail: ckirchner@mfmr.gov.na
}

Manuscript received November 2007; accepted April 2009

\begin{abstract}
This study attempts to explain the variability in recruitment of sardine in the northern Benguela and to develop potential models by including environmental information to predict recruitment. Two different recruitment and spawner number datasets were available: a VPA-developed dataset, for the period 1952-1987, and data from a simple age-structured model for 1992-2007. In all, four environmental indices were used: the degree of the intrusion of the warm Angola Current into northern Namibia, termed the Angola-Benguela front index; the extent of the upwelling area off central Namibia; average sea surface temperature (SST) over the northern and central Namibian shelf; and wind stress anomalies at Lüderitz as an indicator of upwelling strength. Contrary to general belief, it was found that extremely high recruitment can happen at low spawner levels. This occurred in years in which a large upwelling area existed in association with the minimum southward intrusion of the Angola Current. These effects override the normal negative linear relationships with SST and the positive linear relationship with wind. However, when the area of upwelling is average or small, the effects of spawner biomass, SST and wind become important factors in the variability of recruitment. To estimate exceptional recruitment, the upwelling and front indices were included in the model. To measure medium and weak recruitment, spawner numbers and the SST and wind anomaly formed part of the model. These models can be used simultaneously to predict recruitment before annual acoustic surveys take place and thus aid management decisions.
\end{abstract}

Keywords: Angola-Benguela front, environmental parameters, Namibian sardine, recruitment, SST anomalies, upwelling index, wind

Introduction

The southern African sardine Sardinops sagax has formed the basis of an important fishing industry in Namibia since the late 1940s (Crawford et al. 1987). During the late 1950s and 1960 s, the stock level was estimated at several million tonnes (Thomas 1986, le Clus et al. 1988). Sardine are mainly used in the canning industry and catches have risen very rapidly from about 200000 t during the early 1950s to a maximum of 1.4 million $t$ in 1968 (Thomas 1986). Catches decreased considerably to around $50000 \mathrm{t}$ in the late 1970s to the late 1980s. There was a minor recovery during the early 1990s, with catches of around $100000 \mathrm{t}$, but catches continued to decline and in 2002 a one-year moratorium on all sardine fishing in Namibian waters was implemented (De Oliveira et al. 2007). Since then, catches have been below $30000 \mathrm{t}$ and with no signs of recovery.

Since the late 1970s, landings consisted mainly of the first four year classes (le Clus et al. 1988) and more recently of only one to two year classes. Thus, the fishery has in the recent past relied heavily on the annual recruitment. The modal length of sardine catches taken between 1952 and 1957 was $26 \mathrm{~cm}$ total length, with some attaining lengths of up to $29.5 \mathrm{~cm}$ (Matthews 1960). However, more recently there have been very few individuals larger than $26 \mathrm{~cm}$ landed and the modal length between 1997 and 2000 was only $21 \mathrm{~cm}$ (Boyer et al. 2001), confirming the reduced size structure of the population.

During peak biomass years, dense sardine shoals occurred throughout the northern Benguela region, between Lüderitz and the Angola-Benguela front (Boyd and Cruickshank 1983, Beckley and van der Lingen 1999). Since the decline, the stock distribution has been confined to only a few small areas along the Namibian coast (Hampton 2003).

Historically, spawning was concentrated around two main areas, off central Namibia (Walvis Bay region, $23^{\circ} \mathrm{S}$ ), where older fish spawn in early summer, and off northern Namibia (Palgrave Point, $20^{\circ} 30^{\prime} \mathrm{S}$ ), where younger adults spawn during late summer/autumn (Matthews 1964, O'Toole 1977, le Clus 1990b, 1991) (Figure 1). However, these spawning 
patterns are not within rigid boundaries because of the high variability in the timing of the peak spawning in the northern and southern areas (le Clus 1990a). According to Bakun's triad hypothesis (Bakun 1996), the Walvis Bay region has most of the characteristics required for spawning, i.e. the coastline follows a slightly concave orientation and the shelf is fairly wide (Boyd et al. 1987), which creates a relatively sheltered area conducive to near-surface thermal stratification (le Clus 1990a). Upwelling activity is much less intense in this area compared with other areas farther north (i.e. Cape Frio $19^{\circ} \mathrm{S}$ ) and south (i.e. Lüderitz $26^{\circ} 30^{\prime} \mathrm{S}$ ). Thus, the resultant Ekman offshore transport is also less in the Walvis Bay region (Parrish et al. 1983). Farther north, at Palgrave Point, strong stabilisation of the water column occurs under diminished wind conditions, and usually in summer. However, that region is more exposed and the shelf is narrower, and its closer proximity to the AngolaBenguela frontal zone and the strong upwelling centre off Cape Frio makes it more variable than the central area off Walvis Bay.

Juvenile and young adult sardine migrated northwards to the Palgrave Point area, where they spawned first, and the older adults return south to spawn near Walvis Bay. Crawford et al. (1987) suggested that spawning off Walvis Bay decreased after the collapse of the fishery during the mid-1970s. Walvis Bay has always been the activity centre of the pelagic fishing industry and the high fishing pressure associated with this area may have resulted in a depletion

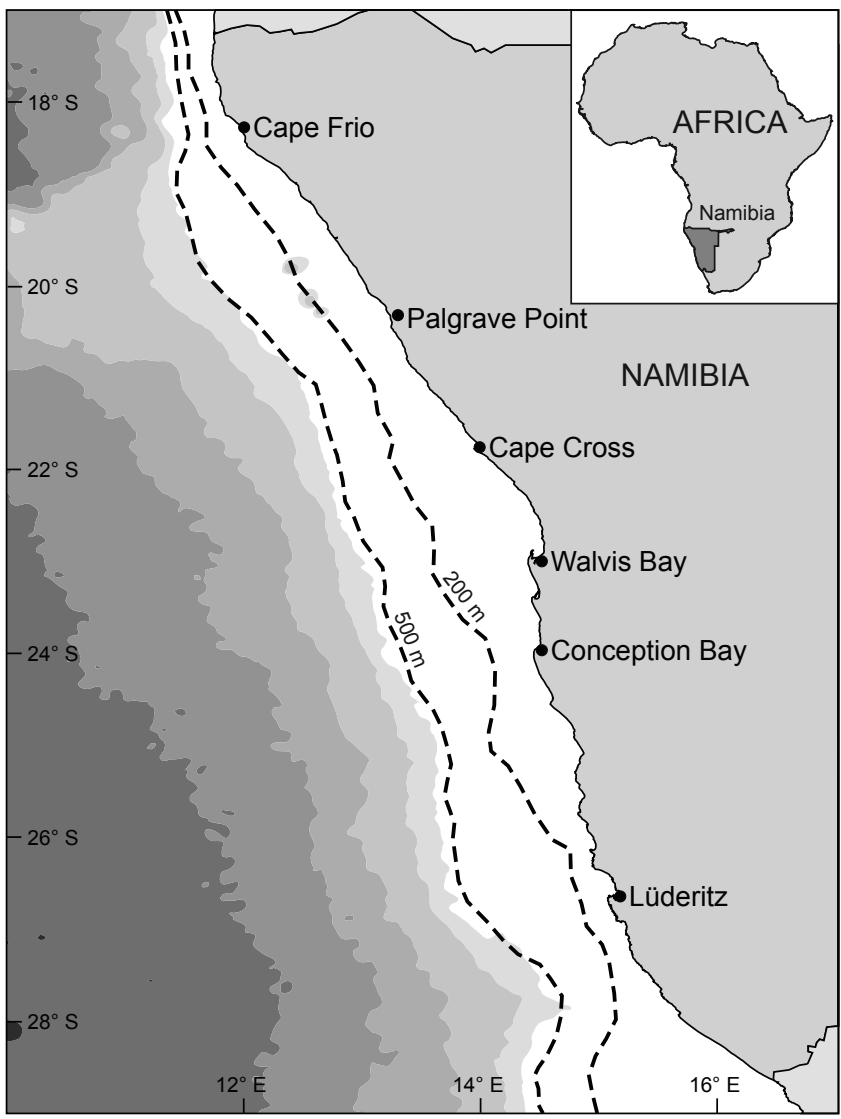

Figure 1: Map indicating the coastline of Namibia of the southern spawning population (King 1977, O'Toole 1977). However, during the 1980s, after the collapse of the stock, sardine appeared to spawn within the same range as they did during the 1960s, and only during cool years did sardine spawn mainly in the northern areas (le Clus 1990a). Gonadosomatic information for the 1980s and 1990s (Kreiner et al. 2001), as well as backdated birth-date information of young fish (Hardmann-Mountford et al. 2003), indicates that spawning peaks at the same time of the year. However, information on spawning location is very limited for the 1990s and 2000s. As the fishing season for sardine is open from March to August, which falls outside their peak spawning period, very limited information on the distribution of the spawning stock can be obtained from the fishing industry. Egg and larval surveys conducted from 2000 to 2005 showed that early life stages of sardine are distributed along the entire coast between $23^{\circ} \mathrm{S}$ and the Kunene River (Stenevik et al. 2005, Kreiner et al. 2009).

Sardine recruitment in the northern Benguela exhibits large interannual variability (Boyer et al. 2001), which has affected the fishing industry because the stock size and resulting total allowable catch (TAC) depend heavily on the annual recruitment. Recruitment from the 1991/1992, 1995/1996, 1996/1997 and 2001/2002 spawning seasons have been exceptionally good, especially considering the small size of the spawning stock during those periods. No clear spawner stock-recruit relationship could be established for the sardine over the past 15 years (De Oliveira et al. 2007), and it is possible that environmental conditions during and after the spawning season could be the driving force for recruitment success, especially with the current low spawner stock biomass. Thus, a better understanding or assessment of the influence of environmental conditions on recruitment success of sardine could improve current sardine management procedures.

There have been several investigations into the relationship between sardine recruitment and environmental variables in the northern Benguela. Le Clus (1990) showed that negative sea surface temperature (SST) anomalies caused spawning activity to decrease near Walvis Bay. Le Clus (1991) showed a dome-shaped relationship between sardine spawning (number of eggs) and thermal stratification. Cole (1999) used mean weekly SST satellite images to help explain the variability of recruitment from 1981 to 1987. Hardmann-Mountford et al. (2003) examined the role of spatio-temporal oceanographic variability on recruitment success by applying a neural network pattern-recognition technique on satellite-derived sea level data for the period 1993-1999. Although this analysis was based on only seven data points, Hardmann-Mountford et al. (2003) concluded that moderate upwelling and a weak Angola Current intrusion were optimal for successful recruitment. Daskalov et al. (2003) investigated a large-scale perspective using two indices, SST in the tropical Atlantic and coastal wind stress at Lüderitz, to relate to sardine recruitment. They concluded that prior to the mid-1980s, sardine recruitment strength was positively correlated with SST and negatively with wind, and that subsequently these relationships were reversed. They suggested a switch between environmental regimes or a change in population behaviour of the depressed sardine stock as reasons for these patterns. 
According to De Oliveira et al. (1998), the stock-recruit relationship tends to dominate in terms of the impact on the performance of the management procedure for South African sardine, considering uncertainties. The stock-recruit estimates obtained from the Namibian sardine assessment described in De Oliveira et al. (2007) are unable to distinguish between any conventional stock-recruit relationships. To provide management advice, recruitment for predictions has to be simulated and therefore some assumptions about recruitment dependence are essential.

The objective of this paper is to gain a better understanding of the influence of the environment on recruitment. Recruitment must at least in part be dependent on the spawning biomass, so it is interesting that in the three years of exceptional recruitment (1996, 1997 and 2002), there were extremely low biomass levels. This unexpected result was investigated. The study is in three parts: it attempts to fit conventional spawner-recruit relationship to historic data; it investigates relationships with four alternative environmental indices; and it develops models that can be used for recruitment prediction.

\section{Material and methods}

\section{Spawner and recruitment estimates}

Sardine off southern Africa have been exploited since 1952, but directly comparable estimates of spawner numbers (2-year-old fish) and recruitment (0-year-old fish) over the entire time period are not available. Estimates are available from 1952 to 1987 and from 1992 to 2008 (Figure 2) using two different assessment methods. No spawner estimates are available from 1988 to 1991 . The limitation (described below) of the estimates for the period 1952-1987 were recognised and therefore these were only used for illustrative purposes and qualitative comparisons, whereas those for the period 1992-2007 were used further in statistical analysis. Because the result of this analysis is to be used in the current stock assessment model, all analyses are in terms of fish numbers rather than biomass.
Estimates of the number of spawners for the first period (1952-1987) were made during the time that the International Commission for the Southeast Atlantic Fisheries (ICSEAF) was responsible for the regulation of marine resources in the South-East Atlantic. These estimates were obtained using virtual population analysis (VPA) (Gulland 1965) and are described in Butterworth $(1979,1980)$ and le Clus and Thomas (1981). A constant natural mortality value of $0.5 \mathrm{y}^{-1}$ was used throughout, for reasons described in Butterworth (1978). A matrix of numbers-at-age (le Clus et al. 1988) from 1952 to 1987 was used in this analysis. Estimates prior to 1970 are subject to uncertainty because age-length data have only been available since 1970 (Thomas 1986). However, tagging and aerial/acoustic estimates showed a fair agreement with the trend of the VPA-estimated biomass (Thomas 1986). Using a single age-length key for the years prior to 1970 smoothed out the years of good and bad recruitment. Recruitment estimates (in numbers) were obtained by the same stock assessment techniques as those used for the spawner numbers. Using the VPA, the estimated 0 -year-old fish were taken as recruitment. The spawner numbers of the same year produce the recruitment of that year.

For the second time period (1992-2007), a simple alternative age-structured model, using Hypothesis 1 as described in De Oliveira et al. (2007), was used. Although those authors considered their Hypothesis 4 to have a superior fit than Hypothesis 1, with the additional data (annual catch and acoustic survey information, 2005-2007), this was no longer the case. This model is based on only two age classes because of clear modes in the length frequency data and the lack of age data. This assessment provides estimates for fish older than two years, which were taken as the number of spawners (Table 1). The model (De Oliveira et al. 2007) estimates recruitment for every year individually, which is related to a survey recruitment index. This survey index is obtained on an annual basis from the survey conducted in spring (October/November), which assesses the adult stock and provides a recruitment index (Kreiner and Boyer 2001, Boyer et al. 2003). Estimated 0-year-old

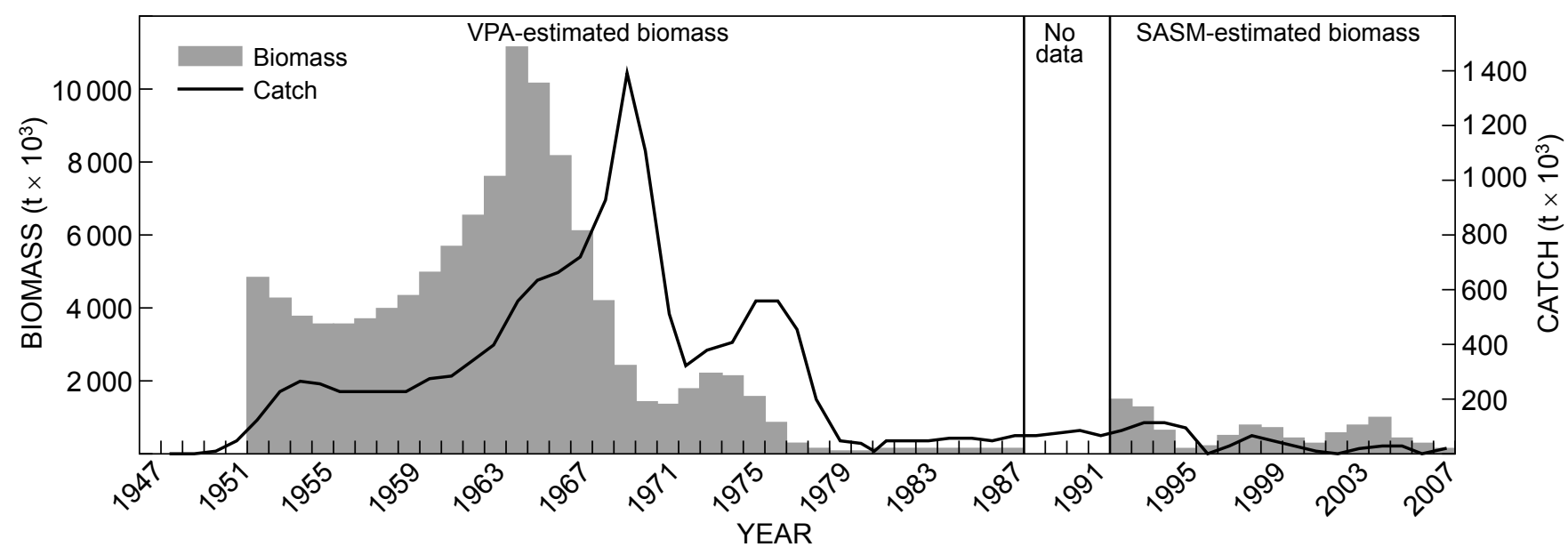

Figure 2: Biomass estimates from 1952 to 1987 (VPA-estimated, le Clus et al. 1988) and from 1992 to 2007 using the method described in De Oliveira et al. 2007 as well as catches taken throughout this period (VPA = virtual population analysis, SASM = simple age-structured model) 
fish are used as proxy for recruitment and the number of spawners in one year produce the 0-year-old fish in the same year (De Oliveira et al. 2007) (Table 1).

\section{Angola-Benguela front index}

The Angola-Benguela front is the boundary area between the cold Benguela upwelling system to the south and the warm subtropical Angola Current to the north. Sardine is an upwelling-dwelling species and is confined to the area south of the front. In summer, the front migrates southwards as upwelling relaxes off northern and central Namibia and in winter/spring it is farther north in southern Angola as upwelling intensity intensifies over that area. The AngolaBenguela front index is an approximation of the monthly position of the front, using the latitudinal position of the $21^{\circ} \mathrm{C}$ isotherm along the coast over a $1^{\circ}$-wide coastal stretch of water, estimated from satellite-derived SST images (Bartholomae and van der Plas 2007). A similar index (warm-water intrusion index 1, WI1) has been used by Voges et al. (2002), but calculated over a $72 \mathrm{~km}$-wide

Table 1: Estimated recruitment and spawner numbers using the De Oliveira et al. (2007) model (1992-2007), upwelling and front indices (1983-2007) and SST and wind anomalies from 1960 to 2007

\begin{tabular}{|c|c|c|c|c|c|c|}
\hline Year & $\begin{array}{c}\text { Recruitment } \\
\left(10^{9}\right)\end{array}$ & $\begin{array}{c}\text { Spawner } \\
\text { numbers }\left(10^{3}\right)\end{array}$ & $\begin{array}{l}\text { Upwelling } \\
\text { index }\end{array}$ & $\begin{array}{l}\text { Front } \\
\text { index }\end{array}$ & $\begin{array}{c}\text { SST } \\
\text { anomaly }\end{array}$ & $\begin{array}{c}\text { Wind } \\
\text { anomaly }\end{array}$ \\
\hline$\overline{1960}$ & & & & & -0.46 & -0.32 \\
\hline 1961 & & & & & -0.26 & -0.02 \\
\hline 1962 & & & & & -0.95 & 0.39 \\
\hline 1963 & & & & & -0.43 & 1.18 \\
\hline 1964 & & & & & -0.15 & 0.01 \\
\hline 1965 & & & & & -0.96 & 0.15 \\
\hline 1966 & & & & & 0.38 & -0.38 \\
\hline 1967 & & & & & 0.92 & 0.50 \\
\hline 1968 & & & & & 0.16 & -0.88 \\
\hline 1969 & & & & & 0.48 & -0.49 \\
\hline 1970 & & & & & 0.22 & -0.24 \\
\hline 1971 & & & & & 0.13 & -0.13 \\
\hline 1972 & & & & & -0.87 & 0.30 \\
\hline 1973 & & & & & -0.16 & -0.78 \\
\hline 1974 & & & & & -0.86 & 0.66 \\
\hline 1975 & & & & & -0.46 & 0.08 \\
\hline 1976 & & & & & 1.15 & -0.33 \\
\hline 1977 & & & & & -0.43 & -0.29 \\
\hline 1978 & & & & & 0.01 & -0.98 \\
\hline 1979 & & & & & 1.80 & -0.25 \\
\hline 1980 & & & & & 0.62 & -0.92 \\
\hline 1981 & & & & & 0.98 & -0.38 \\
\hline 1982 & & & & & 1.19 & -0.66 \\
\hline 1983 & & & 1.75 & -15.67 & 1.53 & -1.22 \\
\hline 1984 & & & 1.87 & -16.67 & 0.32 & 0.26 \\
\hline 1985 & & & 3.83 & -16.00 & -0.21 & -0.33 \\
\hline 1986 & & & 1.76 & -16.00 & 0.67 & -0.85 \\
\hline 1987 & & & 4.38 & -15.00 & 0.98 & -1.30 \\
\hline 1988 & & & 2.07 & -16.33 & 0.55 & 0.01 \\
\hline 1989 & & & 3.20 & -16.50 & -0.65 & 0.88 \\
\hline 1990 & & & 2.20 & -16.00 & -0.72 & 0.24 \\
\hline 1991 & & & 2.35 & -16.00 & 0.22 & -0.36 \\
\hline 1992 & 31.84 & 5622 & 3.19 & -15.33 & 0.03 & -0.72 \\
\hline 1993 & 9.36 & 6705 & 0.15 & -16.50 & -0.77 & 0.29 \\
\hline 1994 & 3.15 & 4119 & 2.64 & -16.17 & -0.97 & 0.39 \\
\hline 1995 & 0.29 & 1242 & 1.61 & -17.50 & -0.71 & 1.08 \\
\hline 1996 & 32.59 & 124 & 2.81 & -16.83 & -0.25 & 0.80 \\
\hline 1997 & 33.3 & 23 & 3.27 & -15.00 & 0.98 & -0.61 \\
\hline 1998 & 18.09 & 2775 & 0.50 & -16.67 & 0.56 & -0.09 \\
\hline 1999 & 7.86 & 3445 & 2.03 & -16.83 & -0.22 & 0.32 \\
\hline 2000 & 5.09 & 2475 & 2.69 & -16.83 & -0.17 & 0.61 \\
\hline 2001 & 7.37 & 1238 & 0.68 & -16.83 & -1.19 & 0.25 \\
\hline 2002 & 62 & 755 & 5.91 & -15.50 & -1.32 & 0.49 \\
\hline 2003 & 2.61 & 876 & 2.31 & -16.00 & -0.69 & 0.09 \\
\hline 2004 & 16.82 & 5806 & 2.36 & -16.00 & -0.55 & -0.73 \\
\hline 2005 & 1.34 & 1826 & 1.19 & -16.67 & -0.83 & 0.20 \\
\hline 2006 & 0.74 & 1917 & 1.82 & -16.83 & -0.44 & 0.18 \\
\hline 2007 & 4.19 & 684 & 0.08 & -16.67 & -0.15 & 0.11 \\
\hline
\end{tabular}


coastal band of water. The average position of the $21^{\circ} \mathrm{C}$ isotherm, representing the meridional position of the front, was calculated for the main spawning season of sardine (October-March). This index gives an indirect measurement of the size of the northern Benguela upwelling area and provides additional information on the spatial dynamics of upwelling over the northern Benguela region. For example, in warm years, the front would be located farther south and result in a smaller northern Benguela upwelling area than in cooler years when the front is farther north.

\section{Upwelling index}

An upwelling index was calculated for the central Namibian shelf region $\left(22^{\circ}-24^{\circ} \mathrm{S}, 12^{\circ}-14^{\circ} \mathrm{E}\right)$, similar to that described by Voges et al. 2002 (upwelling index 2, UW2). In this case, the percentage area where offshore and inshore temperatures differed between $3{ }^{\circ} \mathrm{C}$ and $12^{\circ} \mathrm{C}$ was used as a proxy for the size of suitable upwelling area over the central Namibian shelf. As for the front index, these values were averaged over the main spawning season of sardine (October-March), resulting in a single upwelling index for each spawning season.

\section{SST index}

Monthly SST data derived from NOAA satellite data were used to calculate a SST index over the central Namibian shelf region $\left(22^{\circ}-24^{\circ} \mathrm{S}, 12^{\circ}-14^{\circ} \mathrm{E}\right)$ by averaging the SST values over this area and between January and March for each season since 1982. This time period is when warm-water intrusions into northern Namibia are most common and upwelling intensity is lowest, and it also coincides with the latter part of the sardine spawning season. This time-series was extended backwards to 1960 using the Comprehensive Ocean-Atmosphere Data Set, and a nine-year overlap period between 1982 and 1990 was used to verify the compatibility and correspondence between the two datasets.

\section{Wind index}

The Lüderitz upwelling cell is the strongest in the Benguela system and is active throughout the year, with a slight relaxation in winter (Parrish et al. 1983). Monthly standardised wind stress anomalies derived from wind data collected at Diaz Point near Lüderitz for the past 48 years (Peard 2007) were used as a proxy of upwelling strength. As for the SST index, the wind stress anomalies were averaged over January and March for each season.

\section{Current spawner number recruitment assumptions and calculations}

Both the Beverton and Holt (1957) and Ricker (1954) stockrecruit assumptions were made for the first time period (1952-1987) to evaluate a historic relationship between spawner numbers and recruitment. These functions were fitted to the stock-recruit estimates derived from a VPA analysis based on historic catch-at-age data (Table App.1.1; le Clus et al. 1988).

The Beverton and Holt relationship is computed as:

$$
N_{0}(y)=\frac{a \times N_{2+}(y)}{\left(b+N_{2+}(y)\right)}
$$

where $a$ is the maximum recruitment produced and $b$ is the spawner numbers where recruitment is half of maximum. Spawner numbers are denoted by $N_{2+}(y)$ and recruitment numbers as $N_{0}(y)$ for year $y$.

The Ricker relationship is given by:

$$
N_{0}(y)=\alpha \times N_{2+}(y) \times \mathrm{e}^{-\beta \times N_{2+}(y)}
$$

where $\alpha$ is the recruits-per-spawner at low stock sizes and $\beta$ describes the rate at which the recruits-per-spawner drop as $N_{2+}(y)$ increases.

\section{Environmental indices and recruitment assumptions and calculations}

Correlations and autocorrelations were carried out on all the datasets used for the period 1992-2007. After careful consideration of any possible non-linear relationships between recruitment and the environmental parameters, recruitment was linearly regressed with the four environmental indices described above. Wind and SST anomalies are available from 1960 (Table 1), therefore they could be regressed with part of the recruitment data available for the period 1960-1987. The upwelling and front indices are available from 1983, and recruitment of the second time period (1992-2007) was linearly regressed with all four environmental indices. The least-squares method was used to determine the best-fitting straight line:

$$
N_{0} \mathrm{obs}(y)=\mathrm{env} \times \delta+\mathrm{c}
$$

where env is the environmental parameter, $\delta$ is the gradient and $c$ the intercept of the regression.

A multivariate regression model with an interaction term was fitted to recruitment $\left(N_{0}\right)$ against the upwelling and front indices using the statistical package SPSS ${ }^{\circledR}$ Base 9.0:

$$
N_{0} \text { est }=\mu+\alpha \times \text { fro }(y)+\eta \times \text { upwel }+v \times(\text { fro } \times \text { upwel })+\varepsilon
$$

where $\alpha$ is the front factor, $\eta$ is the upwelling index factor and $\mu$ is the intercept. An interaction ( $v$ ) between the front and upwelling indices was included. The assumption was made that the error $\varepsilon$ is normally distributed.

A further multivariate regression model with an interaction term was fitted to recruitment $\left(N_{0}\right)$ against spawner numbers $\left(N_{2+}\right)$, and SST and wind anomalies:

$$
\begin{aligned}
N_{0} \text { est } & =\mu+\beta \times N_{2+}(y)+\alpha \times \operatorname{SST}(y)+\eta \times \operatorname{wind}(y) \\
& +v \times\left(S_{S T} \times \text { wind }\right)+\varepsilon
\end{aligned}
$$

where $\beta$ is the spawner numbers factor, $\alpha$ is the SST anomaly, $\eta$ is the wind anomaly and $\mu$ is the intercept. An interaction (v) between the SST and wind anomalies was included. The assumption was made that $\varepsilon$ is normally distributed.

\section{Results}

The biomass estimates shown in Figure 2 of the two time periods were not directly comparable; however, they provided a qualitative view of the trend in the northern Benguela sardine stock. Since the early 1970s, the total biomass of the sardine stock decreased markedly and, 
although there have been small peaks since 1990, the stock has never recovered to its historic levels. Even though catches were kept low since 1978, the sardine biomass remained at depleted levels (Figure 2).

Both the Ricker (Figure 3a) and Beverton and Holt curves were fitted to the historic VPA estimates (1952-1987) and explained $59 \%$ and $58 \%$ of the variation in the historic recruitment respectively. Recruitment can therefore be estimated by

$$
\begin{aligned}
& N_{0}(y)=\frac{52.63 \times N_{2+}(y)}{\left(19390+N_{2+}(y)\right)} \quad \text { (Beverton and Holt) } \\
& N_{0}(y)=0.0023 \times N_{2+}(y) \times \mathrm{e}^{-0.0000255 \times N_{2+}(y)} \quad \text { (Ricker) }
\end{aligned}
$$

However, the residuals (Figure $3 b$ ) clearly showed that the data points were not spread randomly around the estimated Ricker curve, but rather there was a time period of high recruitment followed on by a time period of low recruitment (autocorrelation). Thus, these models alone were inappropriate to predict recruitment. Since 1965, recruitment was estimated to be low, irrespective of the high spawner numbers. These recruitment values were regressed with the wind and SST anomalies data from 1960 to 1987 and it was found that recruitment was weak at positive wind and negative at SST anomalies (Figure 4).

Figure 5 illustrates the stock recruitment data from 1992 to 2007 and it is clear that at extremely low spawner numbers, there was exceptionally high recruitment for the years 1996, 1997 and 2002. This pattern is contradictory to the conventional assumption that at low biomass levels recruitment is directly dependent on spawner biomass. However, if these three years were excluded from the analysis, 39\% ( $p=$ 0.022 ) of the variation in recruitment could be explained by the spawner numbers (Figure 5 ). It is evident that these exceptionally high recruitment years were independent of spawner numbers and therefore alternative explanatory variables were explored.

The correlations between the four environmental indices as well as recruitment and spawner numbers are shown in Appendix 2 (Tables App.2.1 and App.2.2). It is shown that SST and the front indices were highly correlated, so they were not used simultaneously in an analysis. There was very little to no autocorrelation found in the datasets (Table App.2.3). In addition to spawner numbers, linear regressions were performed on recruitment vs wind and SST anomalies, and upwelling and front indices, including all data points as well as excluding the three exceptional recruitment years from the regressions. When all the data points were included, the wind and SST anomalies did not show a significant linear regression, with recruitment at $r^{2}=0.01(p=0.694)$ and $0.04(p=0.450)$ respectively (Figure 6a, c). However, with the exclusion of the 1996, 1997 and 2002 data, regressions of $r^{2}=0.28(p=0.063)$ and $r^{2}=0.60(p<0.002)$ were obtained for the wind and SST anomalies respectively (Figure $6 b, d$ ). In contrast, for the upwelling index, the regression was highly significant with the inclusion of all data points $\left(r^{2}=0.56, p<0.001\right)$, and with the exclusion of the three exceptional years the regression was not significant $\left(r^{2}=0.057, p=0.434\right)$ (Figure $6 e, f)$. The front index regressions were significant
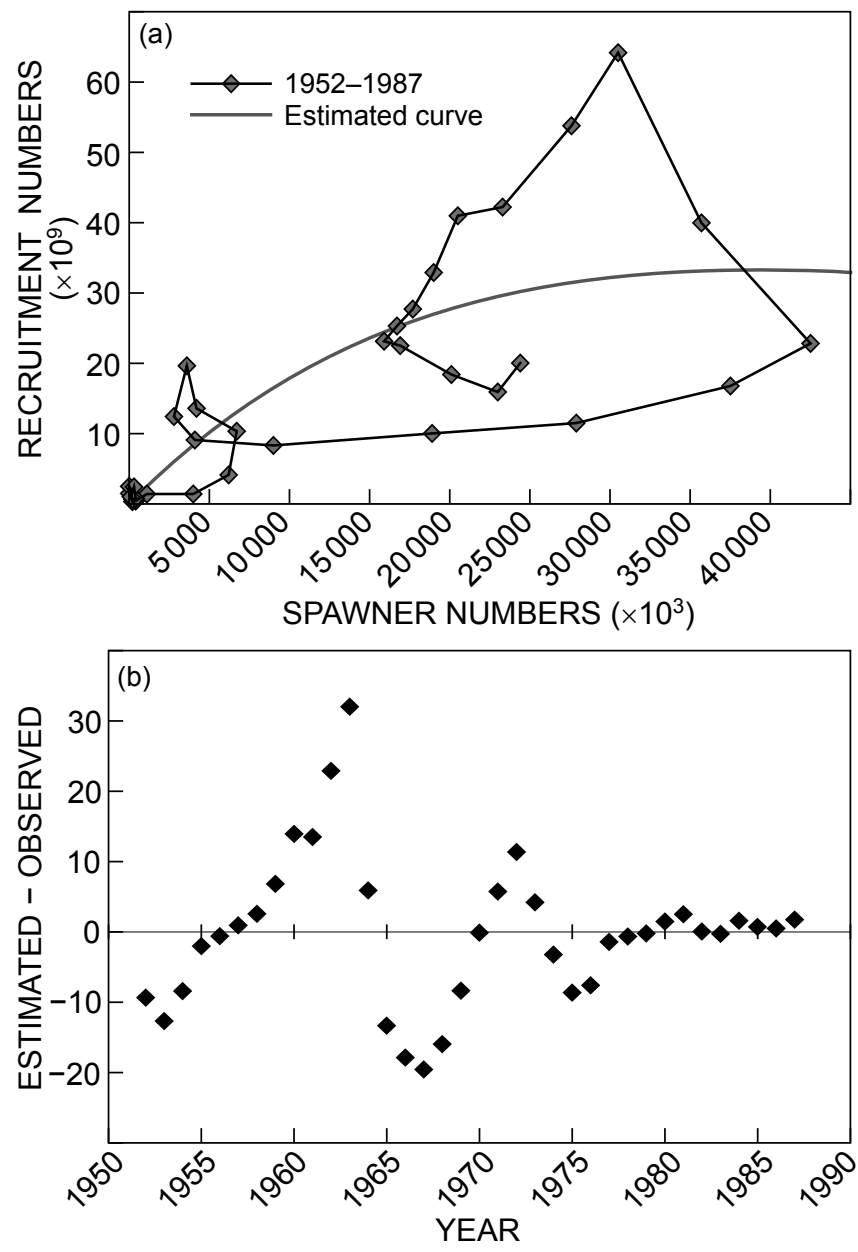

Figure 3: (a) Ricker-fitted stock recruitment graph to data from 1952 to 1987 and (b) residuals between observed and estimated recruitment values

irrespective of whether all the data were included $\left(r^{2}=\right.$ $0.416, p=0.007)$ or excluded $\left(r^{2}=0.46, p=0.012\right)$ (Figure 6g, h).

Multivariate regressions with the inclusion of an interaction were carried out, first by including all the most recent data and using the upwelling and front indices as variables and then by excluding the three exceptional years from the dataset and using spawner numbers, wind and SST as variables. These various models are shown in Tables App.2.4 and App.2.5 respectively.

When all the data were included, the multiple regression showed that with the inclusion of both covariates, the upwelling and front indices, and the interaction between these indices, the model explained $73 \%$ of the variance in the data (adjusted $r^{2}=0.67$; Table 2). However, although the corrected model was significant at $p=0.001$, the intercept and front index had $p$-values of 0.2 , which were not significant at the $5 \%$ level (Table 3). Both upwelling index and the interaction were significant at that level with $p=0.036$ and 0.043 respectively (Table 3 ). This model fits the years 1997 and 2002 well, but the observed 1996 data point is fitted poorly. In addition, the recruitment failures in 1994, 1995 and 2003 are not well fitted by this model (Figure 7). 

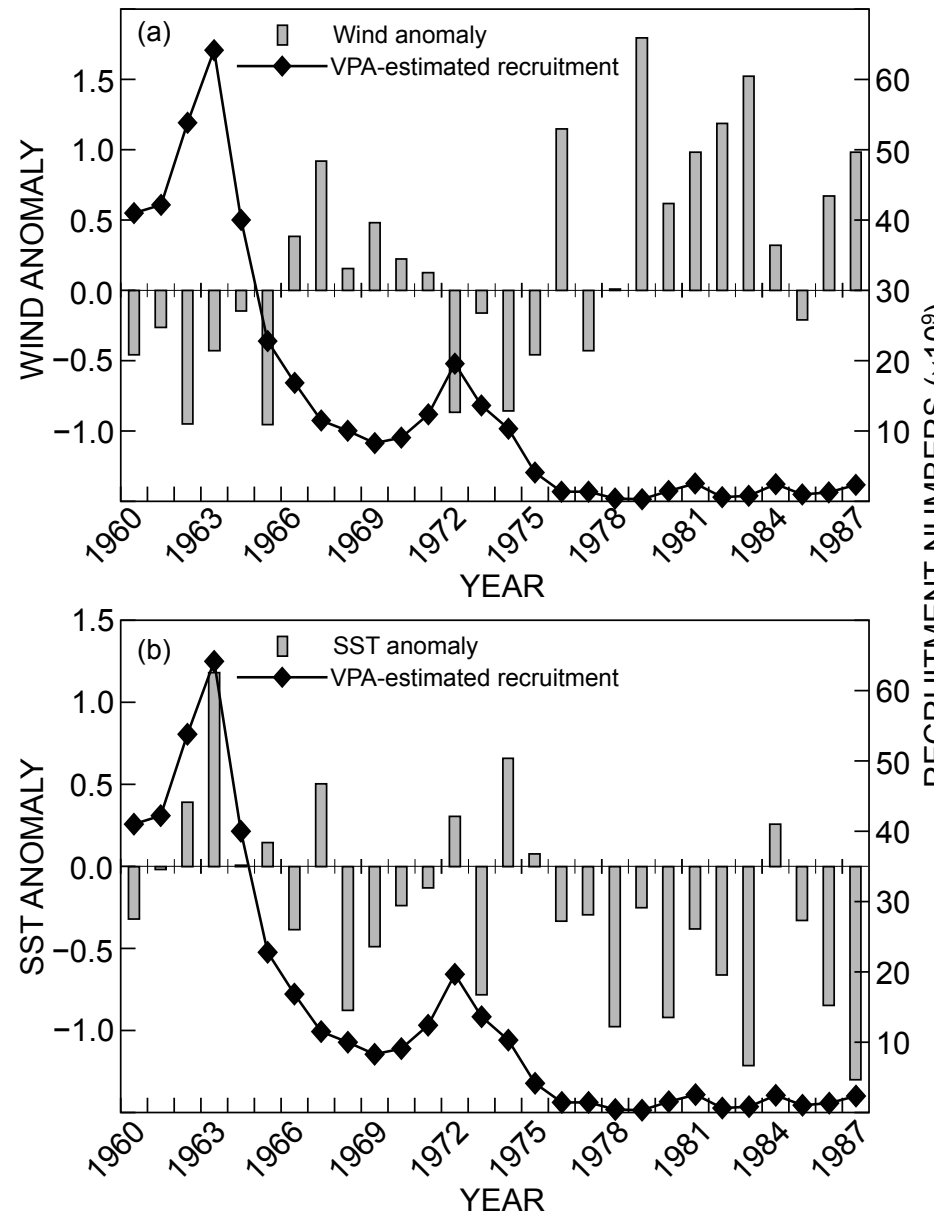
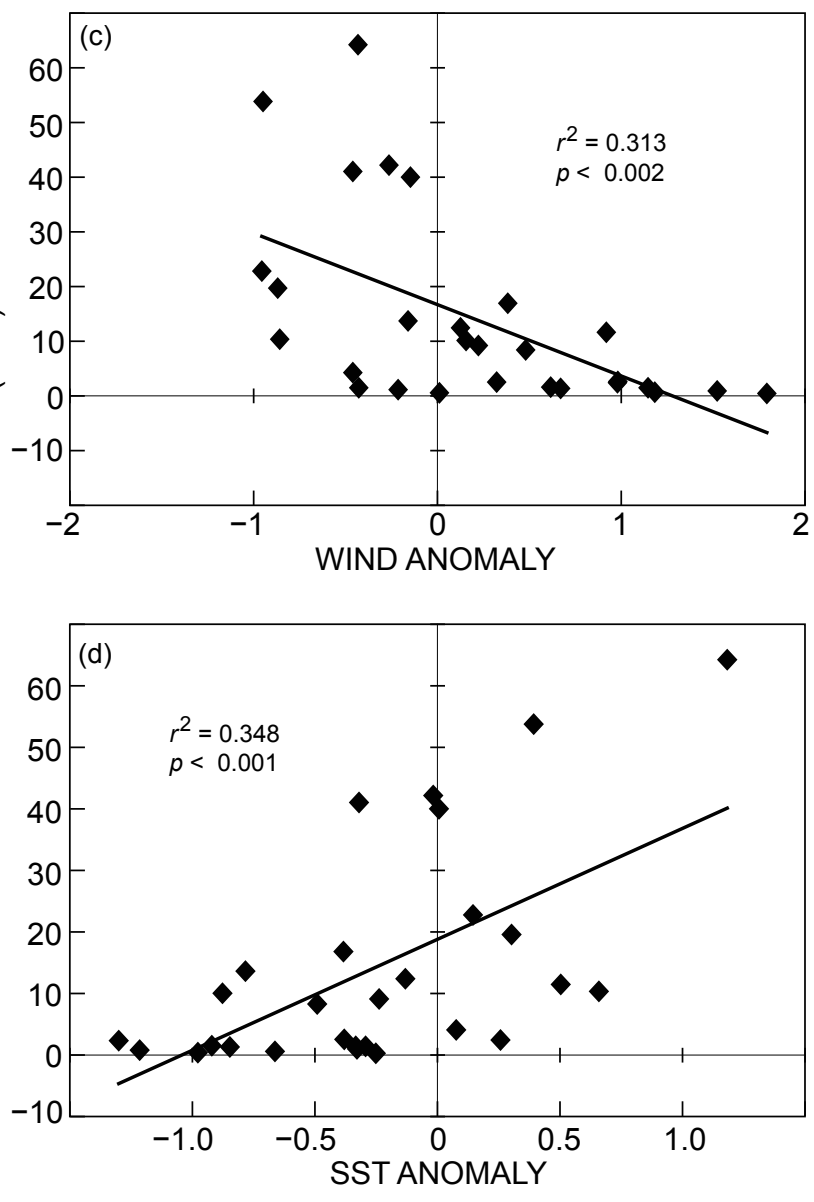

Figure 4: VPA-estimated recruitment data and wind anomaly (upper left) and with SST anomaly (lower left) from 1960 to 1987. Regressions of recruitment versus wind anomaly (upper right) and SST anomaly (lower right)

The model including all the data is described by:

$$
\begin{aligned}
& N_{0}(y)=149.73 \times \text { upwel }(y)-14.98 \times \text { fro }(y)+8.86 \times(\text { upwel }(y) \\
&\times \text { fro }(y))-244.77 \\
&(\text { Model 1) }
\end{aligned}
$$

For the case in which the 1996, 1997 and 2002 data points were excluded and regressed against spawner biomass, wind and SST, and the interaction between wind and SST, the model explained $90 \%$ of the variation and was highly significant $(p=0.0005)$. All the covariates and the interaction were significant (Table 4). The model fitted the observed years of recruitment failure very well.

This model (Figure 8 ) can be described by the following equation:

$$
\begin{aligned}
N_{0}(y) & =0.001 \times \operatorname{SSN}_{2+}(y)+7.98 \times \operatorname{wind}(y)-18.72 \times \operatorname{SST}(y) \\
& -21.41 \times(\operatorname{wind}(y) \times \operatorname{SST}(y))+7.83 \quad(\text { Model } 2)
\end{aligned}
$$

This model was then further used to estimate the three excluded data points as indicated in Figure 8. Again, the 1996 data point was estimated poorly, but this model could also not estimate the extremely high recruitment in 2002 . The 1997 data point was estimated well.

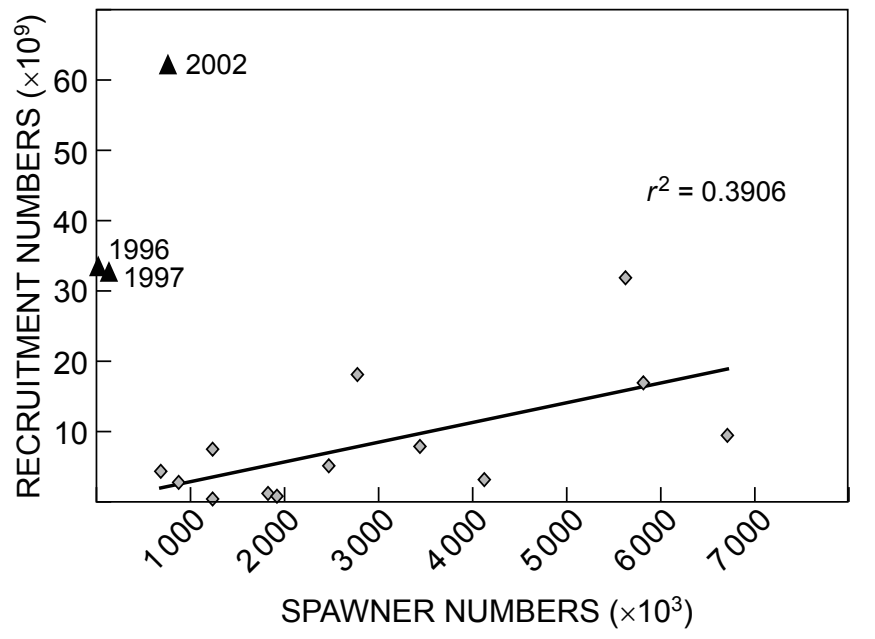

Figure 5: Spawner numbers and recruitment values obtained by following the method described in De Oliveira et al. (2007). The closed triangles denote the years of extremely high recruitment, irrespective of low spawner numbers 

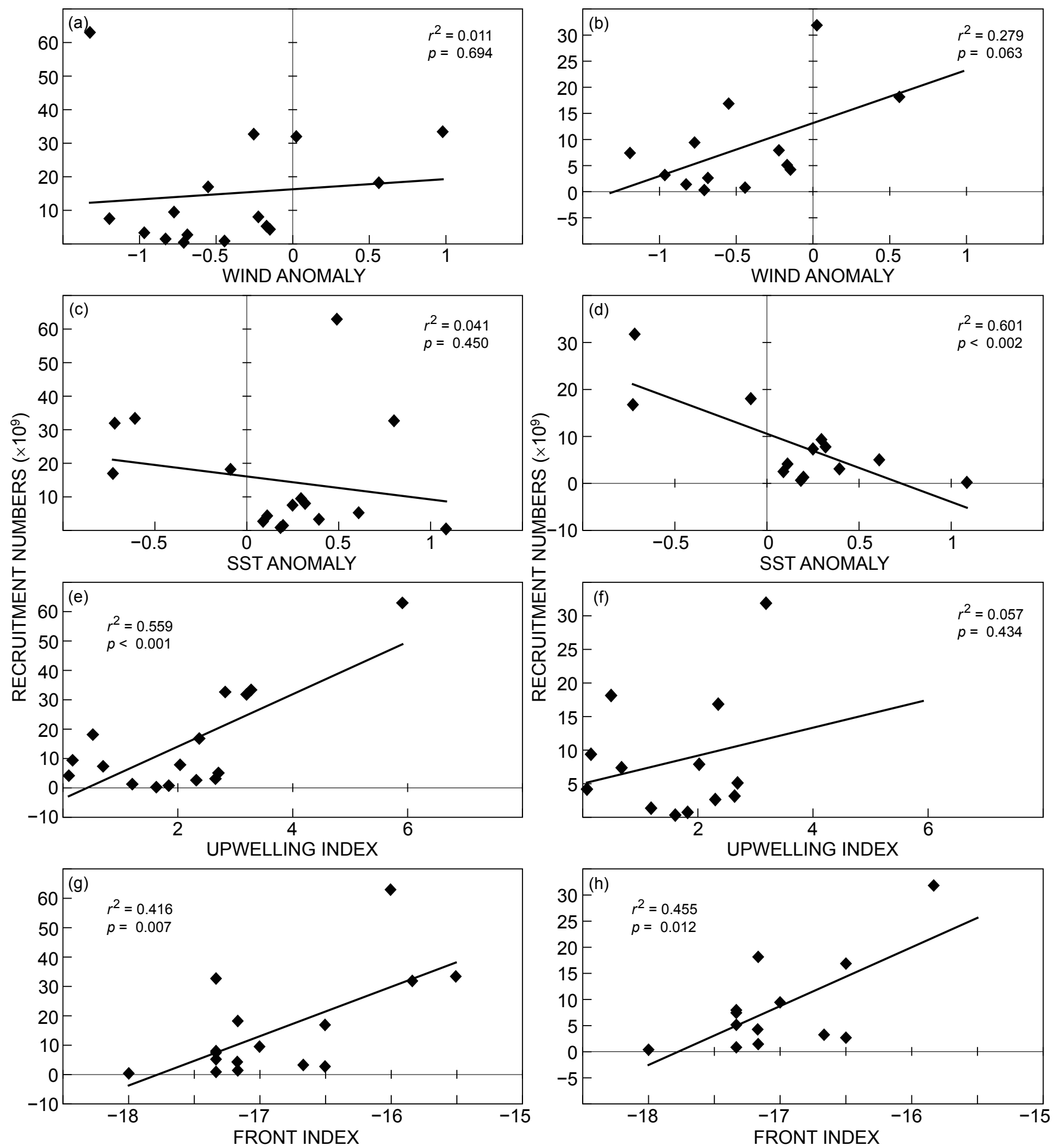

Figure 6: Linear relationships between recruitment and SST and wind anomalies and front and upwelling indices including all data (1992-2007) (left) and excluding 1996, 1997 and 2002 (right)

\section{Discussion}

The Namibian sardine stock has been at very low biomass levels since about 1970 , and apart from a short period of partial recovery in the early 1990 s, the stock has shown no signs of improvement. This may partly be a result of the high catches taken in the 1960s, but it was also due to persistent low recruitment over an extended period of time. During the first half of the 1960s, recruitment was high; however, irrespective of a high spawner biomass, recruitment was estimated to be low for many years thereafter. This pattern suggests a high spawning biomass does not necessarily 
Table 2: Results for the model (including all data) used to estimate recruitment using the upwelling (upwel) and front indices as variables

\begin{tabular}{|c|c|c|c|c|}
\hline \multirow{2}{*}{ Model 1} & \multirow{2}{*}{$\begin{array}{l}\text { Parameter } \\
\text { estimates }\end{array}$} & \multirow{2}{*}{$p$-value } & \multicolumn{2}{|c|}{$\begin{array}{c}95 \% \\
\text { confidence interval }\end{array}$} \\
\hline & & & $\begin{array}{l}\text { Lower } \\
\text { bound }\end{array}$ & $\begin{array}{l}\text { Upper } \\
\text { bound }\end{array}$ \\
\hline $\begin{array}{l}\text { Corrected } \\
\text { model }\end{array}$ & & 0.001 & & \\
\hline Intercept & -244.768 & 0.213 & -650.64 & 161.10 \\
\hline Upwel & 149.732 & 0.036 & 11.47 & 287.99 \\
\hline Front & -14.979 & 0.209 & -39.57 & 9.61 \\
\hline Upwel $\times$ front & 8.863 & 0.044 & 0.30 & 17.42 \\
\hline
\end{tabular}

Computed using $\alpha=0.05$

$r^{2}=0.73$ (adjusted $r^{2}=0.67$ )

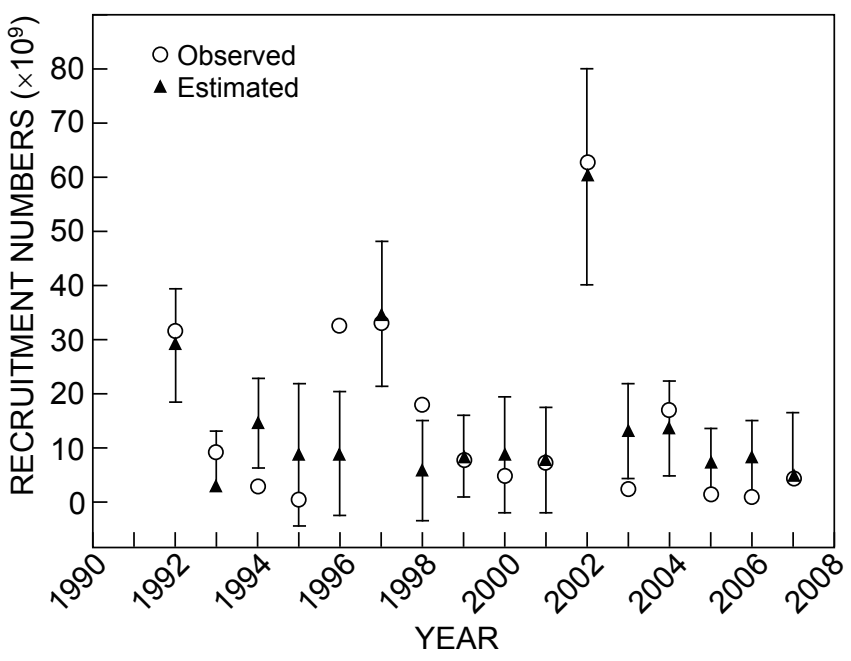

Figure 7: Observed sardine recruitment and model-fitted (Model 1) recruitment with $95 \%$ confidence intervals for the best-fit model using all data points from 1992 to 2007 and regressed against the upwelling and front indices

guarantee good recruitment, so perhaps environmental conditions could be the overriding factor for recruitment success. As found by Daskalov et al. (2003) for the ICSEAF VPA estimates in the northern Benguela, the periods of poor recruitment coincided with conditions of above normal wind stress (Figure 4). This is contrary to what has been the case in more recent years (1992-2007) (Figure 6). The ICSEAF VPA dataset further suggests that there was complete recruitment failure from 1975 to 1987 (Figure 4). This, however, seems unlikely because the sardine stock was estimated at about 1.5 million $t$ in the early 1990 s, so prior to that there had to be some years of strong recruitment. Environmental information used in Model 1 is available from 1983 onwards (Table 1), therefore recruitment from 1983 to 1991 could be estimated. Strong recruitment was estimated for 1985 and 1987 (Figure 9), which could explain the higher biomass values in the early 1990s. The strong recruitment in 1985 was also indicated from egg surveys reported by le Clus (1990a), who suggested that recruitment in 1982 and 1983 was reasonable and not a recruitment failure as indicated by the VPA data.
Table 3: Results for the model (excluding data for years 1996, 1997 and 2002) used to estimate recruitment, using spawner numbers, SST and wind anomalies as variables

\begin{tabular}{|c|c|c|c|c|}
\hline \multirow{2}{*}{ Model 2} & \multirow{2}{*}{$\begin{array}{l}\text { Parameter } \\
\text { estimates }\end{array}$} & \multirow{2}{*}{$p$-value } & \multicolumn{2}{|c|}{$\begin{array}{c}95 \% \\
\text { confidence interval }\end{array}$} \\
\hline & & & $\begin{array}{l}\text { Lower } \\
\text { bound }\end{array}$ & $\begin{array}{l}\text { Upper } \\
\text { bound }\end{array}$ \\
\hline Corrected model & & 0.0005 & & \\
\hline Intercept & 7.833 & 0.009 & 2.51 & 13.15 \\
\hline SST & 7.982 & 0.009 & 2.55 & 13.41 \\
\hline Wind & -18.720 & 0.002 & -28.12 & -9.32 \\
\hline Spawner numbers & 0.001 & 0.047 & 0.00 & 0.00 \\
\hline SST $\times$ wind & -21.406 & 0.016 & -37.67 & -5.14 \\
\hline
\end{tabular}

Computed using $\alpha=0.05$

$r^{2}=0.90$ (adjusted $r^{2}=0.85$ )

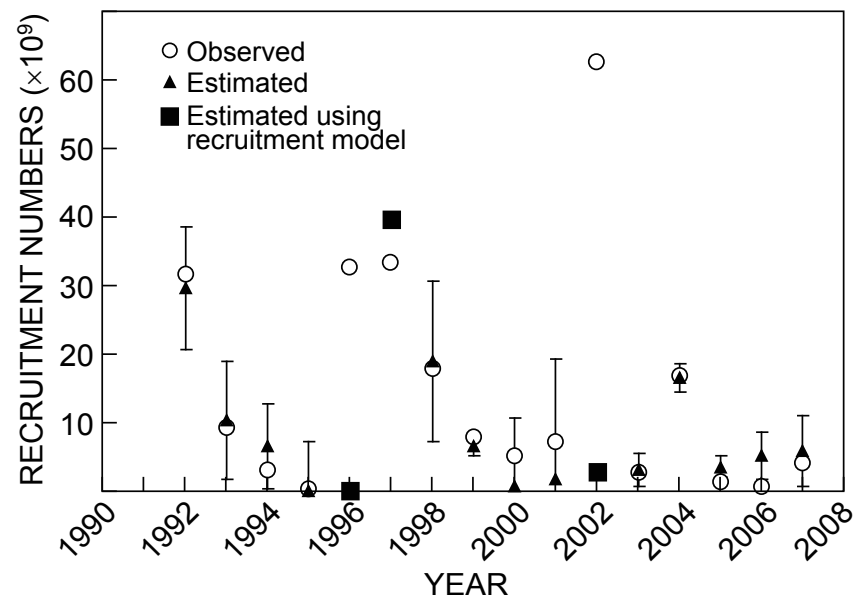

Figure 8: Observed sardine recruitment and model-fitted recruitment with 95\% confidence intervals from 1992 to 2007 for the best-fit model excluding data for 1996, 1997 and 2002. Recruitment was regressed against the spawner numbers, SST and wind anomalies. Recruitment for 1996, 1997 and 2002 was then estimated using this recruitment model (Model 2)

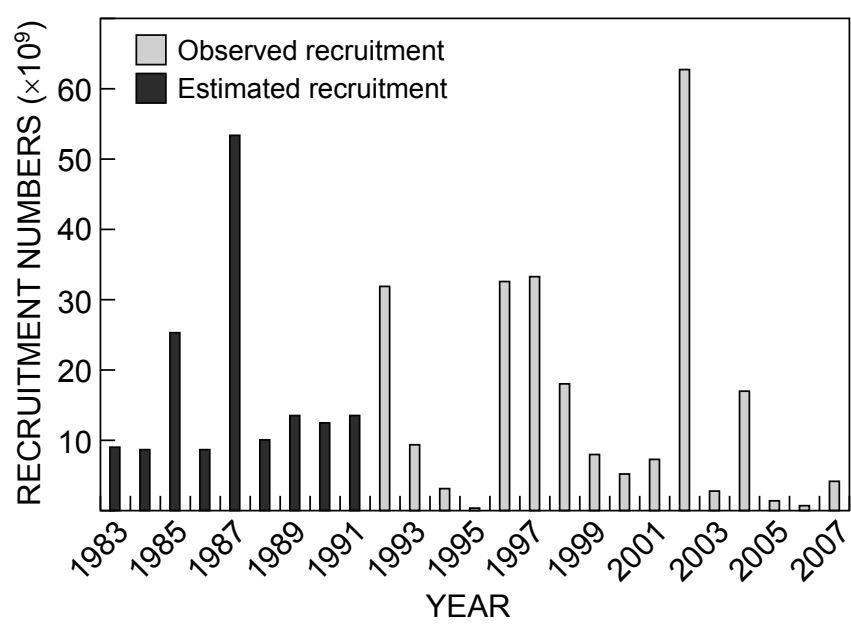

Figure 9: Recruitment obtained using the De Oliveira et al. (2007) model from 1992 to 2007 and estimated recruitment from 1983 to 1991 using Model 1 of this study 
For conventional spawner-recruit relationships (Beverton and Holt 1957, Ricker 1954), there should be a linear relationship between spawner and recruit numbers at low biomass levels. Since the 1970s (with the exception of the early 1990s), only low recruitment would therefore be expected. However, the more recent data (1992-2007) show that exceptionally high recruitment, similar to the levels found in the early 1960s, was obtained in 1996, 1997 and 2002, irrespective of the extremely low spawner biomass in those years. These years were excluded from the dataset for some of our analyses. For the full dataset, there was no correlation between recruitment and spawner numbers nor between recruitment and wind and SST anomalies. However, with the exclusion of these data points, there was a significant, positive linear relationship between recruitment and spawner numbers, as well as wind, as found by Daskalov (2003), and a significant negative correlation with SST on the central Namibian shelf (Figure 5). Recruitment was highly significantly correlated to the front index, irrespective of whether all the data points were included or not. In contrast, the upwelling index was only a significant variable if all the data were included in the dataset (Figure 5). This pattern suggests that in years when the area of upwelling is large, the influence of the effect of wind and SST is irrelevant, but in years of medium or small upwelling areas, the positive SST and negative wind anomalies can cause a complete recruitment failure. However, the influence of the extent of the intrusion of the frontal zone is still an important factor.

Using the complete dataset, recruitment appeared to be highly dependent on the area of upwelling and the movement of the frontal zone into Namibian waters, and the interaction thereof (Model 1). Both the environmental indices were strongly correlated with good recruitment when the area of upwelling off central Namibia was above average, and during seasons when the position of the front was farther north, implying cooler conditions usually associated with stronger upwelling off northern Namibia. Upwelling off central/northern Namibia is not very strong during summer and a high upwelling index value would likely fall within the optimal environmental window as described by Cury and Roy (1989), which correlates well with the good recruitment obtained for these years. A more northerly position of the front during these years (1997 and 2002) would not only imply higher levels of upwelling off central and northern Namibia but it would also present a larger area with favourable conditions along the northern Namibian coast. This is important considering the patchiness of the current sardine stock, i.e. the more area available with favourable environmental conditions the better the chances of selecting such an area during spawning activity. During warmer years, the front would be farther south, as a result of weak upwelling, which not only reduces the upwelling area but also provides space for the influx of nutrient- and oxygen-poor Angolan water. The subsequent increase in SST over northern Namibia would not favour primary production and result in reduced fish larval survival (Boyd et al. 1987, Gammelsrød et al. 1998). Bartholomae and van der Plas (2007) showed that SSTs have increased off northern Namibia during the past decade, especially in summer, which has resulted in fewer years in which cool conditions prevail. The front index provides important information on the spatial dynamics of the northern Benguela upwelling area over the shelf, which is not entirely captured by the upwelling index alone.

The ability to predict recruitment failure is more important for management purposes than to predict years of exceptional recruitment. In periods when the area of upwelling is average and below average, variables such as SST and wind become important factors. A highly significant model (Model 2) was developed using the dataset that excluded the three years of exceptionally high recruitment. The variables, spawner numbers, SST and wind anomalies were used to explain the variance in observed recruitment. This model fits the data of years of medium and poor recruitment very well, but the model does not predict the data for 1996, 1997 and 2002 data adequately (Figure 9).

Neither of the two models could fit the high recruitments observed in the 1996 season. An explanation is that sardine may have invested a lot of energy into spawning as a survival strategy following the extreme Benguela Niño conditions the previous year (Gammelsrød et al. 1998). Upwelling increased towards the second half of 1996 and continued throughout the 1997 season (Bartholomae and van der Plas 2007), which also resulted in good recruitment for that season. It is possible that the strong upwelling during the second half of 1996 improved the survival rate of the juvenile sardine from the 1995/1996 spawning season.

Most stock-recruit relationships that simulate future recruitment are based on the assumption of linearity at lower biomass levels. Until recently, this was also the assumption given for Namibian sardine, which predicted that no recovery of the sardine stock was possible. However, it appears that high recruitment can be obtained at very low spawner number levels and recruitment can fail completely at high spawner number levels, scenarios that should be considered that in management recommendations. All the environmental indices used in this study can be obtained at the end of March of each year. By using Model 1, exceptional recruitment can be predicted and Model 2 can possibly predict years of average and poor recruitment. Using these two models simultaneously will be an improvement on previously used methods for investigating recruitment of sardine in Namibian waters. Using these newly environmentally based recruitment relationships, it is therefore possible to have an estimate of that year's recruitment in April. Measurements of recruitment are obtained in November, following a hydroacoustic survey of the region (Boyer 2001), so these models can be used in management recommendations.

Acknowledgements - We thank the Ministry of Fisheries and Marine Resources in Namibia for making available the data used in this study. We thank our colleagues who contributed towards this paper directly or indirectly, in particular Nadine Moroff.

\section{References}

Bakun A (ed.). 1996. Patterns in the ocean: ocean processes and marine population dynamics. San Diego: University of California Sea Grant Program, in cooperation with Centro de Investigaciones Biológicas de Noroeste, La Paz, Mexico.

Bartholomae $\mathrm{CH}$, van der Plas A. 2007. Towards the development of environmental indices for the Namibian shelf, with special 
reference to fisheries management. African Journal of Marine Science 29: 25-35.

Beckley LE, van der Lingen CD. 1999. Biology, fishery and management of sardines (Sardinops sagax) in southern African waters. Marine and Freshwater Research 50: 955-978.

Beverton RJH, Holt SJ (eds). 1957. On the dynamics of exploited fish populations. Fisheries Investment Series 2, Vol. 19. London: UK Ministry of Agriculture and Fisheries.

Boyd A, Cruickshank RA. 1983. An environmental basin model for West Coast pelagic fish distribution. South African Journal of Science 79: 150-151.

Boyd A, Salat J, Maso M. 1987. The seasonal intrusion of relatively saline water on the shelf off northern and central Namibia. In: Payne AIL, Gulland JA, Brink KH (eds), The Benguela and comparable ecosystems. South African Journal of Marine Science 5: 107-120.

Boyer DC, Boyer H, Fossen I, Kreiner A. 2001. Changes in abundance of the northern Benguela sardine stock during the decade 1999-2000, with comments in the relative importance of fishing and the environment. In: Payne AIL, Pillar SC, Crawford RJM (eds), A decade of Namibian fisheries science. South African Journal of Marine Science 23: 67-84.

Boyer H, Boyer DC, Tjizoo BM. 2003. Cruise report of the R.V. Welwitchia. Sardine survey of the Northern Benguela $\left(16^{\circ} 10^{\prime} \mathrm{S}-\right.$ $\left.24^{\circ} \mathrm{S}\right)$. Unpublished report, Ministry for Fisheries and Marine Resources, Namibia.

Butterworth DS. 1978. A preliminary alternative assessment based upon a revised method of sardine ageing. Collection of Scientific Papers of the International Commission for the Southeast Atlantic Fisheries 5: 45-52.

Butterworth DS. 1979. An assessment of the sardine population in ICSEAF Division 1.4 and 1.5, 1967-1978. Collection of Scientific Papers of the International Commission for the Southeast Atlantic Fisheries 6: 163-170.

Butterworth DS. 1980. The value of catch statistics-based management techniques for heavily fished pelagic stocks with special reference to the recent decline of the Southwest African sardine stock. Collection of Scientific Papers of the International Commission for the Southeast Atlantic Fisheries 7: 69-84.

Cole JFT. 1999. Environmental conditions, satellite imagery and clupeoid recruitment in the northern Benguela upwelling system. Fisheries Oceanography 8: 25-38.

Crawford RJM, Shannon LV, Pollock DE. 1987. The Benguela ecosystem. Part IV. The major fish and invertebrate resources. Oceanography and Marine Biology. An Annual Review 25: 353-505.

Cury P, Roy C. 1989. Optimal environmental window and pelagic fish recruitment success in upwelling areas. Canadian Journal of Fisheries and Aquatic Sciences 46: 670-680.

Daskalov GM, Boyer DC, Roux J-P. 2003. Relating sardine Sardinops sagax abundance to environmental indices in northern Benguela. Progress in Oceanography 59: 257-274.

De Oliveira JAA, Boyer HJ, Kirchner CH. 2007. Developing agestructured stock assessment models as a basis for management procedure evaluations for Namibian sardine. Fisheries Research 85: 148-158.

De Oliveira JAA, Butterworth DS, Roel BA, Cochrane KL, Brown JP. 1998. The application of a management procedure to regulate the directed and bycatch fishery of South African sardine Sardinops sagax. In: Pillar SC, Moloney CL, Payne AIL, Shillington FA (eds), Benguela dynamics: impact of variability on shelf-sea environments and their living resources. South African Journal of Marine Science 19: 449-469.

Gammelsrød T, Bartholomae CH, Boyer DC, Filipe VLL, O'Toole ML. 1998. Intrusion of warm surface water along the AngolanNamibian coast in February-March 1995: the 1995 Benguela Niño. In: Pillar SC, Moloney CL, Payne AIL, Shillington FA (eds),
Benguela dynamics: impact of variability on shelf-sea environments and their living resources. South African Journal of Marine Science 19: 41-56.

Gulland JA. 1965. Estimation of mortality rates. Annex to the Arctic Fisheries Working Group Report, Hamburg, January 1965. ICES Document 1965: 3.

Hampton I. 2003. Harvesting the sea. In: Molloy F, Reinikainen T (eds), Namibia's marine environment. Windhoek: Directorate of Environmental Affairs of the Ministry of Environment and Tourism. pp 31-69.

Hardmann-Mountford NJ, Richardson AJ, Boyer DC, Kreiner A, Boyer H. 2003. Relating sardine recruitment success in the northern Benguela to environmental conditions during spawning estimated from satellite-derived sea surface temperature and height. Progress in Oceanography 59: 241-255.

King DPF. 1977. Distribution and relative abundance of eggs of the South West African sardine Sardinops ocellata and anchovy Engraulis capensis, 1971/72. Fisheries Bulletin of South Africa 9: 23-31.

Kreiner A, Boyer H. 2001. Cruise Report of the R.V. Welwitchia. Sardine survey of the northern Benguela $\left(16^{\circ} \mathrm{S}-25^{\circ} \mathrm{S}\right)$. Unpublished report, Ministry for Fisheries and Marine Resources, Namibia.

Kreiner A, Stenevik EK, Ekau W. 2009. Sardine Sardinops sagax and anchovy Engraulis encrasicolus larvae avoid regions with low dissolved oxygen concentration in the northern Benguela Current system. Journal of Fish Biology 74: 270-277.

Kreiner A, van der Lingen CD, Fréon P. 2001. A comparison of condition factor and gonadosomatic index of sardine Sardinops sagax stocks in the northern and southern Benguela upwelling ecosystems, 1984-1999. In: Payne AIL, Pillar SC, Crawford RJM (eds), A decade of Namibian fisheries science: South African Journal of Marine Science 23: 123-134.

le Clus F. 1990a. Impact and implications of large scale environmental anomalies on the spatial distribution of spawning of the Namibian sardine and anchovy populations. South African Journal of Marine Science 9: 141-159.

le Clus F. 1990b. Hydrographic features related to pilchard and anchovy spawning in the northern Benguela system, comparing three environmental regimes. South African Journal of Marine Science 10: 103-125.

le Clus F. 1991. Spatial variability in the seasonal trends of ovary weight in the Namibian sardine population, 1965-1979. South African Journal of Marine Science 9: 69-83.

le Clus F, Melo YC, Cooper RM. 1988. Impact of environmental perturbation during 1986 on the availability and abundance of pilchard and anchovy in the northern Benguela upwelling system. Collection of Scientific Papers of the International Commission for the Southeast Atlantic Fisheries 15: 49-70.

le Clus F, Thomas RM. 1981. An assessment of the sardine population in ICSEAF Division 1.3, 1.4 and 1.5 in 1980. Collection of Scientific Papers of the International Commission for the Southeast Atlantic Fisheries 8: 103-119.

Matthews JP. 1960. The sardine of South West Africa (Sardinops ocellata): size composition of the commercial catches in South West Africa, 1952-1957. Investigational Report of the Marine Research Laboratory of South West Africa 1.

Matthews JP. 1964. The sardine of South West Africa (Sardinops ocallata). Sexual development, condition factor and reproduction 1957-1960. Investigational Report of the Marine Research Laboratory of South West Africa 10.

O'Toole MJ. 1977. Investigations into some important fish larvae in the south east Atlantic in relation to the hydrological environment. PhD thesis, University of Cape Town, South Africa.

Parrish RH, Bakun A, Husby D, Nelson DS. 1983. Comparative climatology of selected environmental processes in relation to eastern boundary current pelagic fish reproduction. In: Sharp $\mathrm{GD}$, Csirke J (eds), Proceedings of the expert consultations to 
examine changes in abundance and species composition of neritic fish resources, San Jose, Costa Rica, April 1983. FAO Fisheries Report 291(3): 731-777.

Peard KR. 2007. Seasonal and interannual variability of wind-driven upwelling at Lüderitz, Namibia. MSc thesis, University of Cape Town, South Africa.

Ricker WE. 1954. Stock and recruitment. Journal of Fisheries Research Board of Canada 11: 559-623.

Stenevik EK, Fossum P, Endresen B, Kreiner A. 2005. Recruitment studies on anchovy, horse mackerel and sardine in the Northern
Benguela, 13-27 January 2005. Cruise Report of the Dr. Fridtjof Nansen No. 1/2005.

Thomas RM. 1986. The Namibian sardine: the 1985 season, assessment for 1952-1985 and recommendations for 1986. Collection of Scientific Papers of the International Commission for the Southeast Atlantic Fisheries 13: 243-269.

Voges E, Gordoa A, Field JG, Bartholomae CH. 2002. Estimating the probability of different levels of recruitment for Cape hakes Merluccius capensis off Namibia, using environmental indices. Fisheries Research 58: 333-340. 


\section{Appendix 1: The data used}

Table App.1.1: Number of sardine-at-age in the Namibian stock from 1952 to 1987, estimated by VPA reproduced from le Clus et al. (1988)

\begin{tabular}{|c|c|c|c|c|c|c|c|c|c|}
\hline Year & 0 & 1 & 2 & 3 & 4 & 5 & 6 & 7 & 8 \\
\hline 1952 & 20.0 & 15.7 & 8.9 & 6.2 & 3.6 & 1.9 & 1.3 & 0.8 & 1.7 \\
\hline 1953 & 15.9 & 12.1 & 9.5 & 5.3 & 3.4 & 2.0 & 1.0 & 0.7 & 1.1 \\
\hline 1954 & 18.4 & 9.7 & 7.4 & 5.7 & 2.8 & 1.8 & 1.1 & 0.5 & 0.8 \\
\hline 1955 & 22.5 & 11.2 & 5.9 & 4.4 & 3.0 & 1.4 & 1.0 & 0.6 & 0.6 \\
\hline 1956 & 23.1 & 13.6 & 6.8 & 3.5 & 2.3 & 1.5 & 0.7 & 0.5 & 0.6 \\
\hline 1957 & 25.3 & 14.0 & 8.2 & 4.0 & 1.9 & 1.1 & 0.7 & 0.3 & 0.5 \\
\hline 1958 & 27.7 & 15.4 & 8.5 & 4.8 & 2.1 & 0.9 & 0.6 & 0.4 & 0.4 \\
\hline 1959 & 32.9 & 16.8 & 9.3 & 4.9 & 2.5 & 1.1 & 0.5 & 0.3 & 0.4 \\
\hline 1960 & 41.0 & 19.9 & 10.2 & 5.5 & 2.4 & 1.3 & 0.6 & 0.2 & 0.3 \\
\hline 1961 & 42.2 & 24.9 & 12.1 & 6.0 & 2.8 & 1.2 & 0.7 & 0.3 & 0.2 \\
\hline 1962 & 53.8 & 25.6 & 15.1 & 7.1 & 2.9 & 1.4 & 0.6 & 0.3 & 0.2 \\
\hline 1963 & 64.2 & 32.6 & 15.5 & 8.8 & 3.5 & 1.5 & 0.7 & 0.3 & 0.2 \\
\hline 1964 & 40.0 & 39.0 & 19.7 & 8.6 & 4.3 & 1.7 & 0.8 & 0.3 & 0.3 \\
\hline 1965 & 22.8 & 24.3 & 23.6 & 11.4 & 4.5 & 1.7 & 0.7 & 0.3 & 0.3 \\
\hline 1966 & 16.8 & 13.9 & 14.7 & 13.9 & 6.1 & 1.8 & 0.6 & 0.2 & 0.2 \\
\hline 1967 & 11.5 & 10.2 & 8.4 & 8.5 & 7.5 & 2.6 & 0.6 & 0.2 & 0.1 \\
\hline 1968 & 10.0 & 7.0 & 6.1 & 4.5 & 3.9 & 3.2 & 1.0 & 0.1 & 0.1 \\
\hline 1969 & 8.3 & 6.0 & 3.2 & 1.9 & 1.2 & 1.5 & 0.8 & 0.4 & 0 \\
\hline 1970 & 9.1 & 5.0 & 3.1 & 0.5 & 0.2 & 0.1 & 0.1 & 0.1 & 0 \\
\hline 1971 & 12.4 & 5.4 & 2.1 & 0.7 & 0 & 0 & 0 & 0 & 0 \\
\hline 1972 & 19.6 & 6.0 & 2.7 & 0.7 & 0.2 & 0 & 0 & 0 & 0 \\
\hline 1973 & 13.6 & 10.4 & 3.3 & 0.7 & 0.2 & 0 & 0 & 0 & 0 \\
\hline 1974 & 10.3 & 7.6 & 5.3 & 1.2 & 0.1 & 0.1 & 0 & 0 & 0 \\
\hline 1975 & 4.1 & 4.6 & 4.4 & 1.7 & 0.1 & 0 & 0 & 0 & 0 \\
\hline 1976 & 1.4 & 1.5 & 2.4 & 1.3 & 0.3 & 0 & 0 & 0 & 0 \\
\hline 1977 & 1.4 & 0.8 & 0.6 & 0.4 & 0.1 & 0 & 0 & 0 & 0 \\
\hline 1978 & 0.4 & 0.3 & 0.3 & 0.1 & 0 & 0 & 0 & 0 & 0 \\
\hline 1979 & 0.3 & 0.1 & 0.1 & 0.1 & 0 & 0 & 0 & 0 & 0 \\
\hline 1980 & 1.5 & 0.1 & 0 & 0 & 0 & 0 & 0 & 0 & 0 \\
\hline 1981 & 2.5 & 0.7 & 0 & 0 & 0 & 0 & 0 & 0 & 0 \\
\hline 1982 & 0.6 & 1.0 & 0.2 & 0 & 0 & 0 & 0 & 0 & 0 \\
\hline 1983 & 0.8 & 0.3 & 0.4 & 0 & 0 & 0 & 0 & 0 & 0 \\
\hline 1984 & 2.4 & 0.2 & 0.2 & 0.1 & 0 & 0 & 0 & 0 & 0 \\
\hline 1985 & 1.0 & 1.0 & 0.1 & 0 & 0 & 0 & 0 & 0 & 0 \\
\hline 1986 & 1.3 & 0.5 & 0.3 & 0 & 0 & 0 & 0 & 0 & 0 \\
\hline 1987 & 2.3 & 0.7 & 0.2 & 0 & 0 & 0 & 0 & 0 & 0 \\
\hline
\end{tabular}




\section{Appendix 2: Correlations between environmental indices and recruitment}

Table App.2.1: Correlations between recruitment ( $N_{0}$ est), sea surface temperature (SST), Angola-Benguela front (fro), upwelling index (upwel), wind and spawner numbers $\left(N_{2+}\right)$. Correlations in bold are significant $(\alpha=5 \%)$. These correlations were done on the full dataset

\begin{tabular}{|c|c|c|c|c|c|c|c|c|c|c|}
\hline & \multicolumn{2}{|c|}{ SST } & \multicolumn{2}{|c|}{$N_{0}$ est } & \multicolumn{2}{|c|}{ Upwel } & \multicolumn{2}{|c|}{ Fro } & \multicolumn{2}{|c|}{$\mathrm{N}_{2+}$} \\
\hline & $r$ & $p$ & $r$ & $p$ & $r$ & $p$ & $r$ & $p$ & $r$ & $p$ \\
\hline Wind & -0.47 & 0.068 & 0.11 & 0.695 & -0.10 & 0.726 & 0.26 & 0.340 & -0.09 & 0.747 \\
\hline SST & & & -0.20 & 0.450 & -0.03 & 0.900 & -0.71 & 0.002 & -0.37 & 0.158 \\
\hline$N_{0}$ est & & & & & 0.75 & 0.001 & 0.64 & 0.007 & -0.14 & 0.611 \\
\hline Upwel & & & & & & & 0.60 & 0.015 & -0.18 & 0.504 \\
\hline Fro & & & & & & & & & 0.11 & 0.682 \\
\hline
\end{tabular}

Table App.2.2: Correlations between recruitment ( $N_{0}$ est), sea surface temperature (SST), Angola-Benguela front (fro), upwelling index (upwel), wind and spawner numbers $\left(N_{2+}\right)$. Correlations in bold are significant $(\alpha=5 \%)$. These correlations were obtained for the dataset that excluded data for 1996, 1997 and 2000

\begin{tabular}{|c|c|c|c|c|c|c|c|c|c|c|}
\hline & \multicolumn{2}{|c|}{ SST } & \multicolumn{2}{|c|}{$N_{0}$ est } & \multicolumn{2}{|c|}{ Upwel } & \multicolumn{2}{|c|}{ Fro } & \multicolumn{2}{|c|}{$\mathrm{N}_{2+}$} \\
\hline & $r$ & $p$ & $r$ & $p$ & $r$ & $p$ & $r$ & $p$ & $r$ & $p$ \\
\hline$\overline{\text { Wind }}$ & -0.33 & 0.271 & 0.53 & 0.063 & 0.02 & 0.948 & 0.13 & 0.680 & 0.08 & 0.793 \\
\hline SST & & & -0.78 & 0.002 & -0.21 & 0.494 & -0.82 & 0.001 & -0.49 & 0.089 \\
\hline$N_{0}$ est & & & & & 0.24 & 0.043 & 0.67 & 0.011 & 0.62 & 0.022 \\
\hline Upwel & & & & & & & 0.48 & 0.101 & 0.23 & 0.444 \\
\hline Fro & & & & & & & & & 0.55 & 0.054 \\
\hline
\end{tabular}

Table App.2.3: Autocorrelation for recruitment ( $N_{0}$ est), sea surface temperature (SST), Angola-Benguela front (fro), upwelling index (upwel), wind and spawner numbers $\left(N_{2+}\right)$. These autocorrelations for the datasets include all data $($ acf $=$ autocorrelation function; pacf $=$ partial autocorrelation function)

\begin{tabular}{|c|c|c|c|c|c|c|c|c|c|c|c|c|}
\hline \multirow{2}{*}{ Lag } & \multicolumn{2}{|c|}{ Wind } & \multicolumn{2}{|c|}{ SST } & \multicolumn{2}{|c|}{$N_{0}$ est } & \multicolumn{2}{|c|}{ Upwel } & \multicolumn{2}{|c|}{ Fro } & \multicolumn{2}{|c|}{$\mathrm{N}_{2+}$} \\
\hline & acf & pacf & acf & pacf & acf & pacf & acf & pacf & acf & pacf & acf & pacf \\
\hline 0 & 1 & 1 & 1 & 1 & 1 & 1 & 1 & 1 & 1 & 1 & 1 & 1 \\
\hline 1 & 0.52 & 0.52 & 0.13 & 0.13 & -0.06 & -0.06 & -0.30 & -0.30 & -0.02 & -0.02 & 0.38 & 0.38 \\
\hline 2 & 0.00 & -0.36 & -0.31 & -0.33 & -0.14 & -0.15 & 0.12 & 0.03 & -0.28 & -0.28 & -0.13 & -0.32 \\
\hline 3 & -0.26 & -0.11 & -0.36 & -0.30 & -0.37 & -0.40 & -0.07 & -0.02 & -0.31 & -0.35 & -0.46 & -0.36 \\
\hline 4 & -0.50 & -0.44 & -0.22 & -0.29 & -0.06 & -0.19 & -0.30 & -0.36 & -0.24 & -0.46 & -0.19 & 0.15 \\
\hline
\end{tabular}

Table App.2.4: Multiple $r^{2}$ and $p$-values for the different models. These models include all the data. Recruitment is related to the upwelling and Angola-Benguela front index

\begin{tabular}{|c|c|c|c|c|c|c|}
\hline Model & Multiple $r$ & Multiple $r^{2}$ & Adjusted $r^{2}$ & df residual & $F$ & $p$ \\
\hline$N_{0}$ est $=\mu+\alpha \times$ fro $(y)+\eta \times$ upwel $+\varepsilon$ & 0.79 & 0.62 & 0.56 & 13 & 10.61 & 0.002 \\
\hline
\end{tabular}

Table App.2.5: Multiple $r^{2}$ and $p$-values for the different models. The models exclude data for 1996, 1997 and 2000 . Recruitment is related to sea surface temperature (SST), wind and spawner numbers

\begin{tabular}{|c|c|c|c|c|c|c|}
\hline Model & Multiple $r$ & Multiple $r^{2}$ & Adjusted $r^{2}$ & df residual & $F$ & $p$ \\
\hline$N_{0}$ est $=\mu+\eta \times$ wind $(y)+\varepsilon$ & 0.53 & 0.28 & 0.21 & 11 & 4.26 & 0.063 \\
\hline$N_{0}$ est $=\mu+\alpha \times \operatorname{SST}(y)+\varepsilon$ & 0.78 & 0.60 & 0.56 & 11 & 16.55 & 0.002 \\
\hline$N_{0}$ est $=\mu+\beta \times N_{2+}(y)+\varepsilon$ & 0.62 & 0.39 & 0.34 & 11 & 7.05 & 0.022 \\
\hline$N_{0}$ est $=\mu+\alpha \times \operatorname{SST}(y)+\eta \times \operatorname{wind}(y)+\varepsilon$ & 0.83 & 0.68 & 0.62 & 10 & 10.83 & 0.003 \\
\hline$N_{0}$ est $=\mu+\beta \times N_{2+}(y)+\alpha \times \operatorname{SST}(y)+\eta \times \operatorname{wind}(y)+\varepsilon$ & 0.88 & 0.78 & 0.71 & 9 & 10.68 & 0.003 \\
\hline$N_{0}$ est $=\mu+\alpha \times \operatorname{SST}(y)+\eta \times$ wind $(y)+v \times($ SST $\times$ wind $)+\varepsilon$ & 0.91 & 0.83 & 0.77 & 9 & 14.40 & 0.001 \\
\hline$N_{0}$ est $=\mu+\beta \times N_{2+}(y)+\alpha \times \operatorname{SST}(y)+\eta \times$ wind $(y)+v \times($ SST $\times$ wind $)+\varepsilon$ & 0.95 & 0.90 & 0.85 & 8 & 17.62 & 0.000 \\
\hline
\end{tabular}

